\title{
Does splenectomy significantly improve the prognosis of hepatocellular carcinoma patients with hypersplenism? A systematic review and meta-analysis
}

\author{
Xue-Bing Shi ${ }^{1 \#}$, Jin-Kai Feng ${ }^{2 \#}$, Jing-Han Wang ${ }^{1 \#}$, Xiao-Qing Jiang ${ }^{1}$ \\ ${ }^{1}$ Department of Biliary Tract Surgery I, Eastern Hepatobiliary Surgery Hospital, Second Military Medical University, Shanghai, China; ${ }^{2}$ Department \\ of Hepatic Surgery VI, Eastern Hepatobiliary Surgery Hospital, Second Military Medical University, Shanghai, China \\ Contributions: (I) Conception and design: XQ Jiang, JH Wang, XB Shi; (II) Administrative support: XQ Jiang; (III) Provision of study materials or \\ patients: JK Feng, XB Shi; (IV) Collection and assembly of data: JK Feng, XB Shi, JH Wang; (V) Data analysis and interpretation: JK Feng, XB Shi; (VI) \\ Manuscript writing: All authors; (VII) Final approval of manuscript: All authors. \\ "These authors contributed equally to this work. \\ Correspondence to: Xiao-Qing Jiang, MD, PhD. Eastern Hepatobiliary Surgery Hospital, Second Military Medical University, 225 Changhai Road, \\ Shanghai 200433, China. Email: jxq1225@sina.com.
}

Background: Whether hepatocellular carcinoma (HCC) patients with hypersplenism can benefit from splenectomy is unclear. This study aimed at exploring the efficacy and safety of concurrent splenectomy for HCC patients with hypersplenism.

Methods: PubMed, EMBASE and Web of Science databases were systematically searched to compare data on the combination of hepatectomy or transhepatic arterial infusion (TAI) with splenectomy (the splenectomy group) with data on hepatectomy or TAI alone (the non-splenectomy group) for the treatment of HCC with hypersplenism. Prospective clinical trials or retrospective cohort studies from inception to May 10, 2020 were considered eligible for this analysis. The relevant outcomes, including patients' demographics, clinicopathologic characteristics, perioperative indices and long-term outcomes, were independently extracted by two investigators. Publication bias for overall survival (OS) and disease-free survival (DFS) was qualitatively assessed by funnel plots and quantitatively evaluated by Begg's and Egger's tests.

Results: Nine retrospective studies including 1,650 patients were analyzed. Short-term outcomes suggested that the incidence rate of postoperative complications, including portal or splenic vein thrombosis [odds ratio $(\mathrm{OR})=26.28, \mathrm{P}<0.001$ ] and pancreatic injury $(\mathrm{OR}=14.89, \mathrm{P}=0.001)$, was significantly higher in the splenectomy group, whereas the perioperative mortality rate was similar between the splenectomy and non-splenectomy groups $(\mathrm{P}=0.541)$. Long-term outcomes indicated that the occurrence of variceal rehemorrhage $(\mathrm{OR}=0.31, \mathrm{P}<0.001)$ and tumor progress or recurrence $(\mathrm{OR}=0.62, \mathrm{P}=0.001)$ was markedly reduced for patients who underwent splenectomy, while the long-term mortality rates were not statistically different between the two groups $(\mathrm{P}=0.087)$. The prognostic evaluation revealed that the OS and DFS were comparable between the splenectomy and non-splenectomy groups [for OS: hazard ratio (HR) $=0.77,95 \%$ confidence interval (CI): 0.53-1.13; for DFS: HR =0.87, 95\% CI: 0.63-1.19]. Funnel plots suggested an HRs symmetric distribution for OS and DFS. Begg's and Egger's tests confirmed that there was no significant HR publication bias for OS and DFS.

Conclusions: Due to the significant progress in surgical techniques and perioperative care, concomitant splenectomy should be considered as an optional treatment for some HCC patients with hypersplenism.

Keywords: Hepatocellular carcinoma (HCC); hypersplenism; hepatectomy; splenectomy; prognosis

Submitted Oct 04, 2020. Accepted for publication Jan 29, 2021.

doi: $10.21037 /$ atm-20-6748

View this article at: http://dx.doi.org/10.21037/atm-20-6748 


\section{Introduction}

Hepatocellular carcinoma (HCC) is the sixth most common solid malignancy and the fourth leading cause of cancerrelated death worldwide (1). Despite recent years' significant improvements in diagnostic and surgical techniques, and the rapid evolvement of molecular-targeted treatment and immunotherapy, the HCC prognoses remain poor (2). Even worse, more than $85 \%$ of HCC patients in Asia are complicated with liver cirrhosis, which often induces second portal hypertension, hypersplenism and esophagogastric varices (3). Due to the unacceptable complications and unsatisfactory prognosis for HCC patients with hypersplenism treated by surgical resection, the practice guideline from the European Association for the Study of the Liver (EASL) recommends hepatectomy as a treatment of choice for patients with a single HCC that is not associated with clinically significant portal hypertension or hypersplenism (4). Liver transplantation is listed as the firstline treatment option for HCC patients within the Milan criteria and that is unsuitable for resection (5). Nevertheless, due to the great imbalance between liver donors and recipients, and the probability of disease progression during the waiting period, hepatectomy is still performed as an alternative for HCC patients with hypersplenism in some East-Asian countries, especially in Japan and China $(6,7)$.

The characteristics of hypersplenism include splenomegaly and pancytopenia. Splenectomy has been proposed as the standard treatment for patients with hypersplenic thrombocytopenia (platelet counts $<10,000 / \mathrm{mm}^{3}$ ) (8). In addition, many studies have shown that simultaneous splenectomy can help in improving HCC patients' immune function and prolonging their survival $(9,10)$. In this regard, some tertiary referral medical centers from Eastern Asia have carried out combined hepatectomy and splenectomy for a wider spectrum of HCC patients, such as those with hypersplenism $(11,12)$. Moreover, the safety and feasibility of simultaneous hepatectomy and splenectomy were previously reported in several studies $(13,14)$.

Kong et al. (14) suggested that synchronous splenectomy was associated with a significant improvement of overall survival (OS). Contrarily, Xie et al. (15) revealed that it did not lead to a significantly higher OS after concomitant splenectomy when compared with hepatectomy alone. Therefore, it is controversial whether splenectomy can improve the long-term prognosis of HCC patients with hypersplenism. This controversy led us to systematically search relevant studies, summarize their related outcomes and evaluate the impact of splenectomy on the long-term prognosis of HCC patients with hypersplenism, which may assist in surgical decision-making for clinical practice. We present the following article in accordance with the PRISMA reporting checklist (available at http://dx.doi. org/10.21037/atm-20-6748) (16).

\section{Methods}

\section{Search strategy}

Two authors (Jin-Kai Feng and Xue-Bing Shi) independently performed a comprehensive literature search through the PubMed, EMBASE and Web of Science. Database searches were updated on May 10, 2020 and restricted to English written full-text articles. A combination of free text and medical subject heading $(\mathrm{MeSH})$ terms was used. The main search strategy was ("hepatocellular carcinoma" OR "adult liver cancer" OR "hepatoma" OR "carcinoma, hepatocellular" OR "liver carcinoma, adult") AND ("splenectomy" OR "hypersplenism”). The bibliography of the retrieved articles was also reviewed to identify additional unindexed studies.

\section{Selection criteria}

The inclusion criteria were as follows: (I) prospective randomized controlled trials (RCTs) or retrospective cohort studies with accessible full texts; (II) clinicopathologically or radiographically confirmed HCC and hypersplenism; (III) providing sufficient data for outcomes evaluation, including overall survival (OS) and/or disease-free survival (DFS); (IV) the treatment groups were divided into concomitant splenectomy and non-splenectomy groups.

Studies were excluded if they met the following criteria: (I) abstracts, letters, case reports, reviews or nonclinical studies; (II) studies with insufficient hazard ratios (HRs) and 95\% confidence intervals (CIs) data estimation; (III) studies with duplicate data or repeat subjects.

\section{Data extraction and quality assessment}

The titles and abstracts of all candidate citations were screened and evaluated by two independent investigators (Jin-Kai Feng and Xue-Bing Shi). The potentially eligible articles were then obtained for full-text review. Disagreements were resolved by discussion and consensus and confirmed by another co-author (Jing-Han Wang).

The retrieved data from the enrolled studies were recorded 
using a predefined electronic spreadsheet, which included: (I) study characteristics: first author, year of publication, country, number of participants, study design and inclusion period; (II) demographics and clinicopathological features: patients' age and gender, serum hepatitis virology, Child-Pugh classification, tumor characteristics, preoperative white blood cell (WBC) and platelet counts, preoperative levels of alpha-fetoprotein (AFP) and total bilirubin, microvascular invasion (MVI) and esophageal varices, and degree of hypersplenism; (III) operative indices: hepatectomy extent, operative time, amount of intraoperative blood loss, and intraoperative transfusion; (IV) postoperative short-term variables: incidence of total complications, portal or splenic vein thrombosis, pancreatic injury, and in-hospital mortality; (V) postoperative long-term outcomes: WBC and platelet counts, levels of total bilirubin, variceal rebleeding, change of Child-Pugh grade, tumor progress or recurrence, and long-term mortality.

The Cochrane Collaboration's tool was used to assess the methodological quality of RCT (17). The quality evaluation for retrospective cohort studies was based on the modified Newcastle-Ottawa Scale (NOS) (18).

\section{Statistical analysis}

To evaluate the impact of synchronous splenectomy on the long-term prognosis of patients with HCC and hypersplenism, the hazard ratios (HRs) and corresponding 95\% confidence intervals (CIs) for OS and DFS, the primary outcomes of interest in this study, were directly obtained from the results of multivariate Cox analysis of the included studies. If the original studies did not present the survival data in the form of HRs and $95 \%$ CIs, the methods that were described by Parmer et al. (19) were used to estimate HRs from the Kaplan-Meier curves. The pooled odds ratios (ORs) with 95\% CIs and the weighted mean differences (WMDs) with $95 \%$ CIs were appropriately reported for other perioperative and postoperative long-term variables. Cochran's Q test and Higgin's I-squared statistic were calculated to measure the inter-study heterogeneity. Both fixed-effects and random-effects models were used to pool the estimates of effect sizes. $\mathrm{P}<0.1$ or $\mathrm{I}^{2}>50 \%$ suggested significant heterogeneity among the literature and a randomeffects model was selected. Otherwise, the fixed-effects model was adopted (20). Subgroup analyses were conducted based on the year of publication, the type of hazard ratio, hepatitis viral infection, and Child-Pugh classification to explore and explain the potential heterogeneity. Publication bias for OS and DFS was qualitatively assessed by funnel plots and quantitatively evaluated by Begg's and Egger's tests (21). The overall effect size achieved statistical significance if the twosided $\mathrm{P}$ value was less than 0.05 . All statistical analyses were performed using Stata statistical software (version 12.0, Stata Corporation, College Station, TX, USA).

\section{Results}

\section{Study selection procedure}

The specific process of identification for eligible studies is shown in the flow diagram (Figure 1). In our initial broad search, a total of 441 articles were identified from the online databases. After a careful screening of the titles and abstracts, 49 potentially relevant articles were selected for eligibility assessment. Following the review of full texts, 40 articles were excluded due to the absence of available HRs for OS or DFS ( $n=36)$ and overlapping study subjects $(n=4)$. Ultimately, 9 studies that comply with the selection criteria were included in this analysis (12,22-29).

\section{Basic information and methodologic quality}

The basic information and methodologic quality of the included studies are displayed in Table 1 and Table S1. These studies were published in East Asian countries from 1999 to 2019 and all the clinical investigations were retrospective cohort studies, with the time interval of patients' enrollment from 1987 to 2015 . The sample size ranged markedly from 34 to 526 subjects across the studies.

As shown in Table 1, the NOS scores of the included studies ranged from 6 to 8 , with a mean score of 7 points. The primary cause that affected the original studies' quality was associated with a failure to match important confounding factors between groups or a lack of a detailed description of lost to follow-up.

\section{Demographic and clinicopathological characteristics}

In total, 1,650 HCC patients with hypersplenism were included, of whom 465 underwent hepatectomy or hepatic arterial infusion (HAI) with concomitant splenectomy (the splenectomy group) and 1,185 underwent liver resection or HAI alone (the non-splenectomy group). The patients' predominant gender was male, accounting for $81.5 \%$ and $83.8 \%$ in the splenectomy and non-splenectomy groups, respectively. Table S1 summarizes other detailed clinicopathological characteristics of patients in the two treatment groups. 


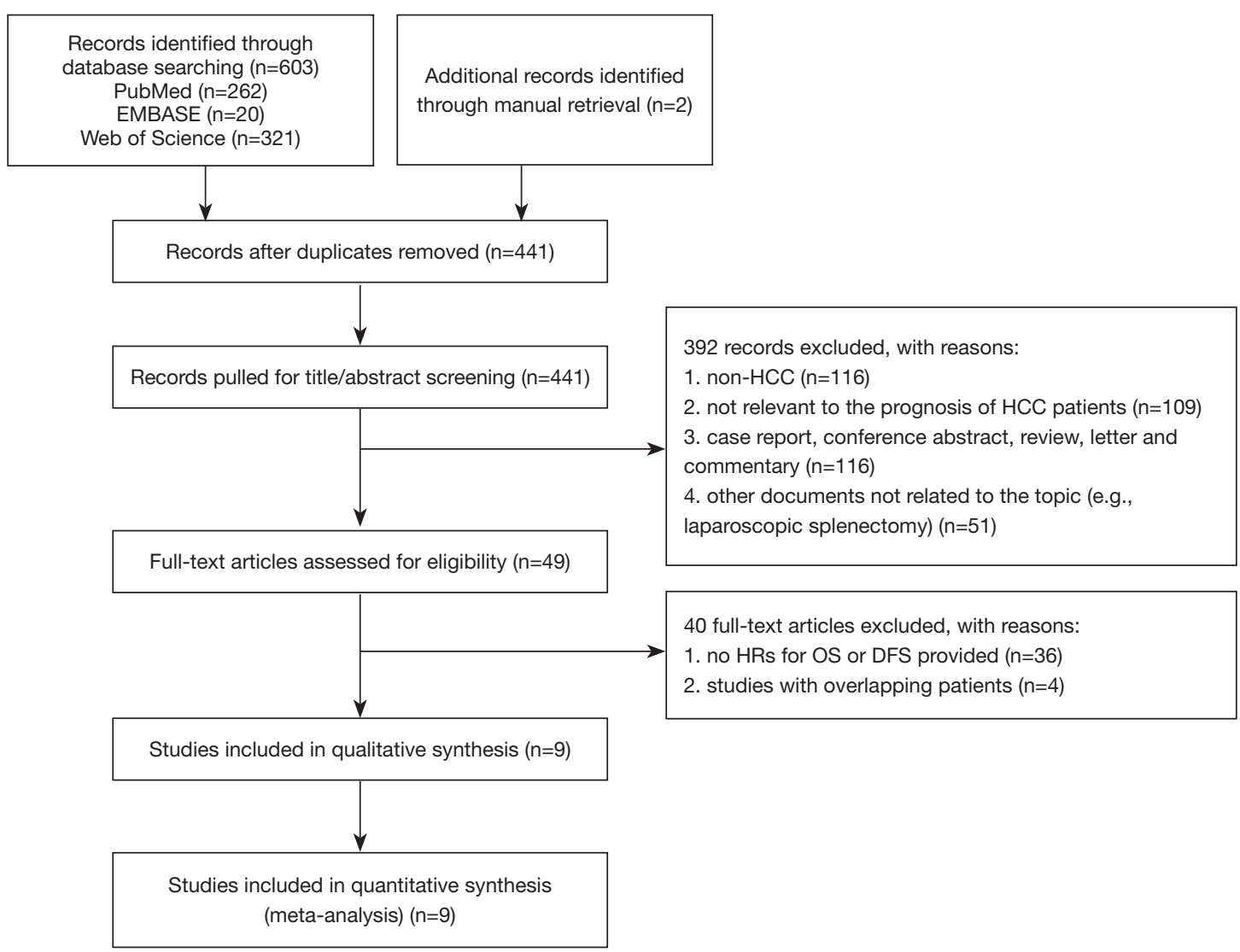

Figure 1 PRISMA flow diagram of the identification process for eligible studies. PRISMA, Preferred Reporting Items for Systematic Review and Meta-Analysis. HCC, hepatocellular carcinoma; HR, hazard ratio; OS, overall survival; DFS, disease-free survival.

Table 1 Basic information and quality assessment of the included studies

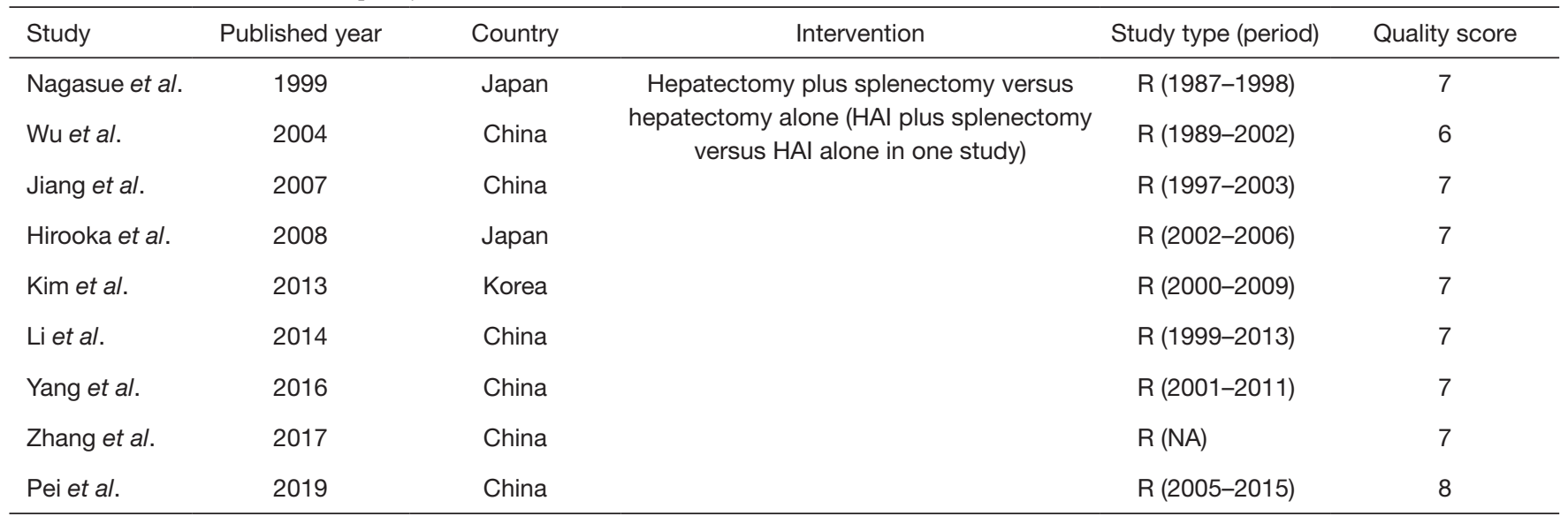

$\mathrm{HAl}$, hepatic arterial infusion; R, retrospective cohort studies; NA, data not available. Quality assessment was based on the modified Newcastle-Ottawa Scale.

As presented in Table 2, no significant differences were found between the splenectomy and non-splenectomy groups in preoperative WBC and platelet counts, and in the level of serum total bilirubin. There were also no marked differences in the proportion of Child-Pugh class A, solitary tumor, and tumor diameter of less than $3 \mathrm{~cm}$ 
Table 2 Summary of meta-analysis comparing HCC patients who underwent splenectomy or not

\begin{tabular}{|c|c|c|c|}
\hline Outcomes of interest [number of studies] & Pooled OR/WMD (95\% Cl) & $\mathrm{P}$ & Heterogeneity $\chi^{2}(\mathrm{P}) / \mathrm{I}^{2}$ \\
\hline \multicolumn{4}{|l|}{ Clinicopathological characteristics } \\
\hline White blood cell $\left(\times 10^{9} / \mathrm{L}\right)[5]^{\dagger}$ & $-1.46(-3.00,0.07)$ & 0.062 & $789.11(<0.001) 99 \%$ \\
\hline Platelet $\left(\times 10^{9} / \mathrm{L}\right)[7]^{\dagger}$ & $-21.52(-82.93,39.89)$ & 0.492 & $8912.95(<0.001) 99 \%$ \\
\hline Total bilirubin $(\mathrm{mg} / \mathrm{dL})[4]^{\dagger}$ & $0.19(-0.11,0.48)$ & 0.214 & $73.54(<0.001) 96 \%$ \\
\hline Solitary tumor [7] & $0.95(0.68,1.33)$ & 0.767 & $3.24(0.778) 0 \%$ \\
\hline Tumor diameter <3 (cm) [4] & $0.96(0.71,1.32)$ & 0.813 & $0.68(0.877) 0 \%$ \\
\hline Microvascular invasion positivity [5] & $0.56(0.38,0.82)$ & $0.003^{*}$ & $3.10(0.540) 0 \%$ \\
\hline Tumor differentiation (well or moderate) [5] & $1.69(1.22,2.34)$ & $0.002^{*}$ & $7.74(0.101) 48 \%$ \\
\hline \multicolumn{4}{|l|}{ Operative variables } \\
\hline Extent of liver resection (minor) [7] & $1.76(1.17,2.65)$ & $0.007^{*}$ & $5.18(0.520) 0 \%$ \\
\hline Operative time $(\mathrm{min})[6]^{\dagger}$ & $42.13(21.50,62.77)$ & $<0.001^{*}$ & $35.37(<0.001) 86 \%$ \\
\hline Intraoperative blood loss $(\mathrm{mL})[6]^{\dagger}$ & $82.19(-106.90,271.29)$ & 0.394 & $125.52(<0.001) 96 \%$ \\
\hline Intraoperative transfusion [7] & $1.89(1.02,3.50)$ & $0.043^{*}$ & $26.23(<0.001) 77 \%$ \\
\hline \multicolumn{4}{|l|}{ Postoperative short-term indices } \\
\hline Total complications [6] & $1.64(1.20,2.25)$ & $0.002^{*}$ & $3.89(0.566) 0 \%$ \\
\hline Platelet $\left(\times 10^{9} / \mathrm{L}\right)[2]^{\dagger}$ & $108.38(93.45,123.32)$ & $<0.001^{*}$ & $2.35(0.125) 58 \%$ \\
\hline Total bilirubin $(\mathrm{mg} / \mathrm{dL})[2]^{\dagger}$ & $-0.09(-0.15,-0.04)$ & $0.001^{*}$ & $0.02(0.876) 0 \%$ \\
\hline Variceal rebleeding [4] & $0.31(0.19,0.51)$ & $<0.001^{*}$ & $1.68(0.642) 0 \%$ \\
\hline Improved Child-Pugh grade [2] & $1.89(0.75,4.73)$ & 0.176 & $2.15(0.142) 54 \%$ \\
\hline Tumor progress or recurrence [8] & $0.62(0.47,0.82)$ & $0.001^{*}$ & $8.83(0.265) 21 \%$ \\
\hline Long-term mortality [7] & $0.78(0.58,1.04)$ & 0.087 & $4.31(0.634) 0 \%$ \\
\hline
\end{tabular}

\footnotetext{
${ }^{\dagger}$ These data were continuous variables and presented as WMD. The others were dichotomous variables and displayed as OR. *P values
} with statistical significance. HCC, hepatocellular carcinoma; OR, odds ratio; WMD, weighted mean difference; Cl, confidence interval.

between the two groups. However, the incidence rates of MVI (OR $=0.56,95 \%$ CI: $0.38-0.82, \mathrm{P}=0.003)$ and slight hypersplenism $(\mathrm{OR}=0.02,95 \% \mathrm{CI}: 0.001-0.40, \mathrm{P}=0.011)$ were significantly lower in the splenectomy group, whereas the percentages of well/moderate tumor differentiation (OR $=1.69,95 \%$ CI: $1.22-2.34, \mathrm{P}=0.002)$ and esophagogastric varices $(\mathrm{OR}=6.22,95 \% \mathrm{CI}: 3.72-10.41, \mathrm{P}<0.001)$ were significantly higher in the splenectomy group. 
A

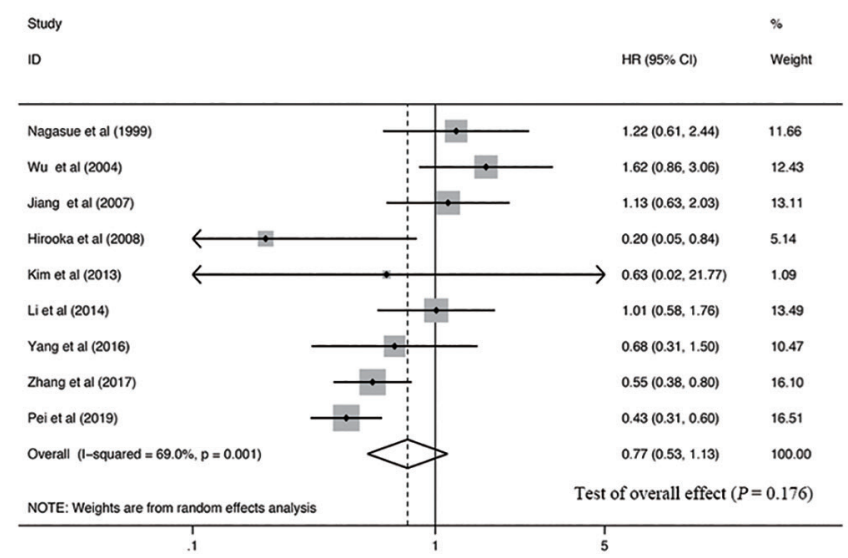

B

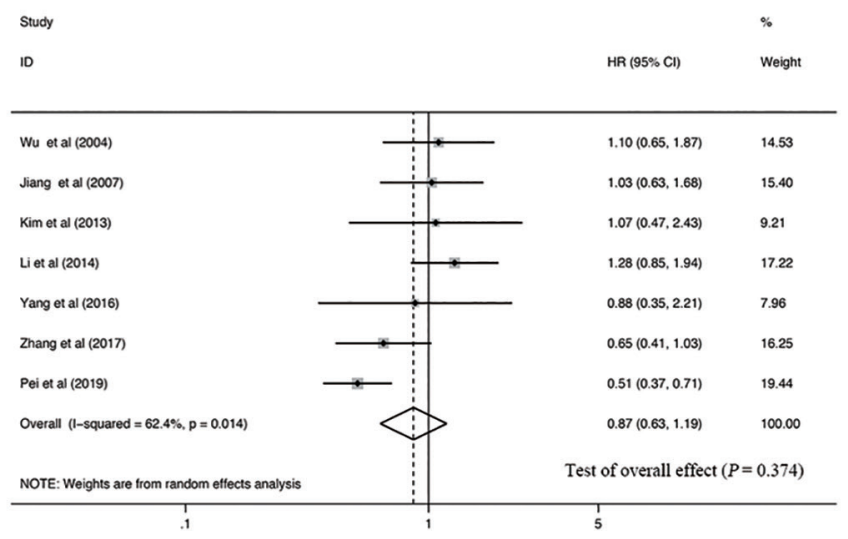

Figure 2 Forest plots of meta-analyses for overall survival and disease-free survival. (A) Forest plot of HR of overall survival; (B) Forest plot of HR of disease-free survival. HR, hazard ratio.

\section{Operative and postoperative short-term variables}

In terms of operative procedures, minor liver resection (OR $=1.76,95 \%$ CI: $1.17-2.65, \mathrm{P}=0.007)$ and intraoperative transfusion ( $\mathrm{OR}=1.89,95 \% \mathrm{CI}: 1.02-3.50, \mathrm{P}=0.043)$ were more commonly encountered in the splenectomy group. Meanwhile, the operative time was significantly longer for patients who received combined splenectomy (WMD $=42.13$, 95\% CI: $21.50-62.77, \mathrm{P}<0.001)$. The amount of intraoperative blood loss was similar between these two groups. Regarding postoperative short-term variables, the incidence rates of total complications $(\mathrm{OR}=1.64,95 \% \mathrm{CI}$ : $1.20-2.25, \mathrm{P}=0.002)$, portal vein or splenic vein thrombosis ( $\mathrm{OR}=26.28,95 \%$ CI: 7.95-86.86, $\mathrm{P}<0.001)$, and pancreatic injury ( $\mathrm{OR}=14.89,95 \% \mathrm{CI}: 3.24-68.40, \mathrm{P}=0.001)$ were significantly increased in HCC patients with hypersplenism who underwent splenectomy, while the perioperative mortality did not show disparity between the two groups.

\section{Postoperative long-term outcomes}

The postoperative hematological and biochemical indices, which were tested 90 days after surgery, showed a significantly higher WBC (WMD =1.68, 95\% CI: 0.38-2.97, P=0.011) and platelet counts (WMD $=108.38,95 \%$ CI: 93.45-123.32, $\mathrm{P}<0.001)$ in the splenectomy group compared to the nonsplenectomy group, whereas the total bilirubin level of patients who underwent splenectomy was significantly lower than that of patients who did not (WMD $=-0.09$, 95\% CI: $-0.15-$ $-0.04, \mathrm{P}<0.001)$. The future possibility of recurrent variceal hemorrhage was significantly reduced in HCC patients with hypersplenism who underwent splenectomy ( $\mathrm{OR}=0.31,95 \%$ CI: 0.19-0.51, $\mathrm{P}<0.001)$. The improvement of liver function, which was indicated by the conversion rate of Child-Pugh grade $\mathrm{B}$ to $\mathrm{A}$, was statistically insignificant between the two groups (OR $=1.89,95 \% \mathrm{CI}: 0.75-4.73, \mathrm{P}=0.176)$. As to the tumor-specific and survival-related parameters, the incidence rate of tumor progress or recurrence was significantly decreased in the splenectomy group ( $\mathrm{OR}=0.62,95 \% \mathrm{CI}$ : 0.47 $0.82, \mathrm{P}=0.001)$. The long-term mortality in the splenectomy group due to any reasons, such as HCC intrahepatic relapse or extrahepatic metastasis, and intractable gastrointestinal bleeding, was relatively lower than its counterpart, although the difference did not reach statistical significance $(\mathrm{OR}=0.78$, 95\% CI: $0.58-1.04, \mathrm{P}=0.087$ ).

\section{Hazard ratio for overall survival and disease-free survival}

To further evaluate the effect of concomitant splenectomy on the long-term prognosis of HCC patients with hypersplenism, HRs for OS and DFS were obtained from each of the included studies and combined with forest plots to generate pooled HRs. As presented in Figure 2, concomitant splenectomy was not a significant prognostic factor of OS and DFS for patients with HCC and hypersplenism (for OS: $\mathrm{HR}=0.77,95 \%$ CI: $0.53-1.13, \mathrm{P}=0.176$, Figure $2 A$; for DFS: $\mathrm{HR}=0.87,95 \%$ CI: $0.63-1.19, \mathrm{P}=0.374$, Figure $2 B$ ).

\section{Subgroup analysis}

The HRs for OS of all studies were divided into various 
subgroups according to the published year (later than 2010 or earlier than 2010), the type of HR (unadjusted univariate $\mathrm{HR}$ or adjusted multivariate $\mathrm{HR}$ ), hepatitis viruses (HBV $>50 \%$ or $\mathrm{HCV}>50 \%$ ) and Child-Pugh classification (class $\mathrm{A}>50 \%$ or class $\mathrm{B}>50 \%$ ).

Stratification by the published year revealed that the studies which were conducted after 2010 significantly favored the splenectomy group (for random-effects model: HR $=0.59,95 \%$ CI: $0.43-0.82, \mathrm{P}=0.002 ; \mathrm{I}^{2}=41.8 \%$; Figure S1A; for fixed-effects model: $\mathrm{HR}=0.55,95 \%$ CI: $0.45-0.69$, $\mathrm{P}<0.001 ; \mathrm{I}^{2}=41.8 \%$; Figure S1B). Stratification by the type of HR demonstrated that patients who were incorporated into the studies with adjusted HR had significantly improved prognosis (for both random-effects and fixedeffects models: $\mathrm{HR}=0.48,95 \%$ CI: $0.37-0.62, \mathrm{P}<0.001$; $\mathrm{I}^{2}=0 \%$; Figure $\left.\mathrm{S} 1 \mathrm{C}, \mathrm{D}\right)$.

The subgroup analysis that was stratified by hepatitis viruses suggested no marked difference in OS between the splenectomy and non-splenectomy groups, regardless of HBV predominance (for random-effects model: $\mathrm{HR}=0.78$, 95\% CI: $0.52-1.17, \mathrm{P}=0.231 ; \mathrm{I}^{2}=70.4 \%$; Figure S2A; for fixed-effects model: $\mathrm{HR}=0.66,95 \% \mathrm{CI}: 0.55-0.81, \mathrm{P}<0.001$; $\mathrm{I}^{2}=70.4 \%$; Figure S2B) and HCV predominance infections (for random-effects model: HR $=0.55,95 \%$ CI: $0.10-3.21$, $\mathrm{P}=0.509 ; \mathrm{I}^{2}=79.8 \%$; Figure S2A; for fixed-effects model: HR $=0.87,95 \%$ CI: $0.46-1.62, \mathrm{P}=0.652 ; \mathrm{I}^{2}=79.8 \%$; Figure $\mathrm{S} 2 \mathrm{~B}$ ). The subgroup analysis that was stratified by Child-Pugh classification disclosed no significant difference in OS between the groups, regardless of Child A predominance (for random-effects model: $\mathrm{HR}=0.86,95 \%$ CI: $0.48-1.53$, $\mathrm{P}=0.600 ; \mathrm{I}^{2}=50.1 \%$; Figure S2C; for fixed-effects model: HR $=0.97,95 \%$ CI: $0.68-1.39, \mathrm{P}=0.883 ; \mathrm{I}^{2}=50.1 \%$; Figure S2D) and Child $\mathrm{B}$ predominance subsets (for random-effects model: $\mathrm{HR}=0.81,95 \% \mathrm{CI}: 0.38-1.71, \mathrm{P}=0.575 ; \mathrm{I}^{2}=83.6 \%$; Figure S2C; for fixed-effects model: $\mathrm{HR}=0.62,95 \% \mathrm{CI}$ : $0.47-0.81, \mathrm{P}<0.001 ; \mathrm{I}^{2}=83.6 \%$; Figure $\left.\mathrm{S} 2 \mathrm{D}\right)$.

\section{Publication bias and sensitivity analysis for OS and DFS}

As shown in Figure S3, a visual inspection of the funnel plots suggested an HRs symmetric distribution for OS and DFS. A quantitative assessment using the Begg's and Egger's linear regression tests confirmed the absence of a significant publication bias of primary outcomes (for OS: Begg's test, $\mathrm{P}=0.917$; Egger's test, $\mathrm{P}=1.000$; for DFS: Begg's test, $\mathrm{P}=0.456$; Egger's test, $\mathrm{P}=0.287$ ).

The HR sensitivity analysis for OS and DFS was further conducted by eliminating each of the included studies in sequence. The results revealed that the HRs values stably fluctuated around the mid-line, demonstrating the stability and robustness of the overall prognostic effect (Figure S4).

\section{Discussion}

The Barcelona Clinic Liver Cancer (BCLC) staging system is the most widely used staging algorithm for HCC management in the real-world practice because of its prognosis predictive ability and its association with treatment allocation (30). It stratifies HCC patients into five different stages (BCLC 0, A, B, C, and D) according to patients' performance status, tumor burden, liver function and so on (30). In this staging system, liver resection is recommended only for patients with a single HCC that is smaller than $5 \mathrm{~cm}$ and without portal hypertension (i.e., BCLC 0 and A1). Liver transplantation is recommended for HCC patients within the Milan criteria (single tumor $\leq 5 \mathrm{~cm}$ or $\leq 3$ tumors with each $\leq 3 \mathrm{~cm}$ in size), and who have clinically significant portal hypertension (presence of a hepatic vein pressure gradient of $\geq 10 \mathrm{mmHg}$ ) (i.e., BCLC A2-A4). In contrast to the prevalent Western guidelines, partial hepatectomy is performed for a broader range of HCC patients, such as those with portal hypertension or hypersplenism, in some East-Asian countries, which is mainly due to the stringent selection criteria for liver transplantation and the unmet need for sufficient liver grafts (6). A recent meta-analysis of 8 studies that included 1,445 HCC patients with hypersplenism showed that the perioperative morbidity and mortality rates were acceptable, and that synchronous splenectomy was associated with a significant improvement of 5 -year OS compared to hepatectomy alone $(\mathrm{OR}=1.81,95 \% \mathrm{CI}: 1.35-2.42, \mathrm{P}<0.001)(14)$. In the present systematic review and meta-analysis, based on 9 retrospective studies with 1,650 patients, we demonstrated that synchronous splenectomy was associated with improved OS and DFS compared to hepatectomy or TAI alone, however, the statistical difference between the two groups was insignificant (for OS: HR $=0.77,95 \%$ CI: $0.53-1.13$, $\mathrm{P}=0.176$; for DFS: $\mathrm{HR}=0.87,95 \%$ CI: $0.63-1.19, \mathrm{P}=0.374$ ).

According to the results of subgroup analysis, the splenectomy group had a significantly better prognosis than the non-splenectomy group during the past ten years (5 out of 9 studies published after 2010) and these data were stable (for random-effects model: $H R=0.59$, 95\% CI: $0.43-0.82, \mathrm{P}=0.002$; for fixed-effects model: HR $=0.55,95 \%$ CI: $0.45-0.69, \mathrm{P}<0.001)$. We suppose that the improvements of surgical techniques, postoperative 
care and research methodology are part of the reasons. Additionally, two studies performed multivariate Cox analysis, and demonstrated that concomitant splenectomy was an independent protective factor for HCC patients with hypersplenism (for both random-effects and fixed-effects models: $\mathrm{HR}=0.48,95 \%$ CI: $0.37-0.62, \mathrm{P}<0.001$ ).

As to the baseline pathological features, there were no significant differences in preoperative $\mathrm{WBC}$ and platelets counts, total bilirubin level, liver function, and tumor burden. Splenomegaly or hypersplenism is a clinical sign characteristic of portal hypertension that is secondary to advanced cirrhosis, which constantly results in pancytopenia. Hypersplenic thrombocytopenia is an indication for splenectomy. Therefore, it is understandable that the degree of hypersplenism was more severe and that the presence of esophagogastric varices was more frequent in the splenectomy group (for slight hypersplenism: OR $=0.02,95 \%$ CI: $0.001-0.40, \mathrm{P}=0.011$; for varices: $\mathrm{OR}$ $=6.22,95 \%$ CI: $3.72-10.41, \mathrm{P}<0.001)$. Interestingly, the pathological data indicated that the splenectomy group of patients had better tumor differentiation (OR $=1.69,95 \%$ CI: $1.22-2.34, \mathrm{P}=0.002)$ and a lower MVI incidence (OR $=0.56,95 \%$ CI: $0.38-0.82, \mathrm{P}=0.003)$. We hypothesize that a possible reason could be that surgeons are more inclined to perform splenectomy on hypersplenic patients who have an earlier stage of HCC, which may explain the underlying selection bias.

Regarding the operative variables, patients in the splenectomy group had a narrower liver resection extent $(\mathrm{OR}=1.76,95 \%$ CI: $1.17-2.65, \mathrm{P}=0.007)$, which may be the result of anatomical considerations associated with surgical safety. Generally, HCC patients with a higher degree of hypersplenism have a higher risk of serious cirrhosis and a lower sufficiency in hepatic functional reserve. Therefore, minor hepatectomy is preferred for this subset of patients to ensure remnant liver volume and to reduce the potential risk of postoperative liver failure.

Previous meta-analyses have suggested that hepatectomy combined with splenectomy does not increase perioperative morbidity and mortality compared to hepatectomy alone $(13,14)$. In the present meta-analysis, we also found a nonsignificant difference in perioperative mortality, whereas the perioperative complications rates, including portal vein thrombosis (PVT) and pancreatic injury, were significantly higher in the splenectomy group. The incidence of postsplenectomy PVT has been reported to range from $2 \%$ to $26 \%$ in cirrhotic patients $(31,32)$. This complication may be fatal if not timely treated. Kim et al. (29) reported that $8(42.1 \%)$ patients in the splenectomy group and 2 (5.1\%) patients in the non-splenectomy group experienced postoperative PVT development, respectively $(\mathrm{P}=0.001)$, and that 2 out of the 10 patients deceased due to PVT. Thus, it is critical to be alert to the possibility of PVT to achieve early detection and treatment (12). Our center suggests that the distal segment of the splenic vein should be as close to the portal vein as possible to reduce stagnation in the remnant splenic vein. The combination of long-term antiplatelet or anticoagulant therapy with regular check-ups is also required after splenectomy (33).

Furthermore, the postoperative long-term outcomes were summarized using a dichotomous approach. The pooled results suggested that $\mathrm{WBC}$ and platelets counts in the splenectomy group were significantly higher than those in the non-splenectomy group, whereas the concentration of total bilirubin in the splenectomy group was significantly lower compared with the control group, demonstrating that the hematological and biochemical indices of HCC patients with hypersplenism were ameliorated following splenectomy. Moreover, the risk of long-term variceal rebleeding was markedly reduced owing to a decrease in portal vein pressure after splenic resection. Notably, there was no significant difference in the long-term mortality rate between the two groups $(\mathrm{OR}=0.78,95 \% \mathrm{CI}: 0.58-1.04$, $\mathrm{P}=0.087$ ). However, the tumor progress or recurrence rate of the splenectomy group was substantially lower than that of the non-splenectomy group ( $\mathrm{OR}=0.62,95 \% \mathrm{CI}: 0.47$ $0.82, \mathrm{P}=0.001)$. Hirooka et al. (12) found that patients in the splenectomy group were more likely to complete full-dose adjuvant therapy due to the improvement of hematological and biochemical indices following concurrent splenectomy, which may be a reasonable explanation for the distinct reduction in the recurrence rate. Nonetheless, given that MVI and tumor differentiation grade, which were reported to be independent predictors for recurrence and OS in HCC patients following curative resection $(34,35)$, were unevenly distributed between the groups, MVI and tumor differentiation could be potential confounders which influenced the long-term survival outcomes.

Several limitations of this analysis need to be carefully considered. First, the included studies were retrospective and did not include RCTs. This limits the capacity to control important confounding factors. In the future, additional high-quality research with adjusted multivariate analyses will be helpful in elucidating the independent impact of splenectomy on the long-term prognosis of HCC patients with hypersplenism. Second, all the studies were 
performed in Eastern Asia, where hepatitis B or C viral infection is the predominant HCC etiology. It is uncertain whether these findings can be extrapolated to Western countries where non-alcoholic fatty liver disease (NAFLD) and non-alcoholic steatohepatitis (NASH) associated HCC is prevalent. Last, a moderate to substantial degree of heterogeneity remained in our study despite the use of subgroup or sensitivity analyses. Therefore, the results should be interpreted with caution.

\section{Conclusions}

In summary, this meta-analysis demonstrated that concomitant splenectomy should be considered as a feasible therapeutic option that is tailored to a carefully selected group of HCC patients with hypersplenism. Although significant improvements of long-term prognosis are not observed, synchronous splenectomy displays some beneficial effects, such as better hematological and biochemical indicators, a reduced risk of variceal re-hemorrhage, and a significant decrease in HCC progress or recurrence rate. In the future, additional well-designed studies with large-scale populations should be conducted to validate our conclusion.

\section{Acknowledgments}

The authors would like to express their gratitude to EditSprings (http://www.editsprings.com/) for the expert linguistic services provided.

Funding: This study was supported by the National Natural Science Foundation of China (No: 81972256).

\section{Footnote}

Reporting Checklist: The authors have completed the PRISMA reporting checklist. Available at http://dx.doi. org/10.21037/atm-20-6748

Peer Review File: Available at http://dx.doi.org/10.21037/ atm-20-6748

Conflicts of Interest: All authors have completed the ICMJE uniform disclosure form (available at http://dx.doi. org/10.21037/atm-20-6748). The authors have no conflicts of interest to declare.

Ethical Statement: The authors are accountable for all aspects of the work in ensuring that questions related to the accuracy or integrity of any part of the work are appropriately investigated and resolved.

Open Access Statement: This is an Open Access article distributed in accordance with the Creative Commons Attribution-NonCommercial-NoDerivs 4.0 International License (CC BY-NC-ND 4.0), which permits the noncommercial replication and distribution of the article with the strict proviso that no changes or edits are made and the original work is properly cited (including links to both the formal publication through the relevant DOI and the license). See: https://creativecommons.org/licenses/by-nc-nd/4.0/.

\section{References}

1. Bray F, Ferlay J, Soerjomataram I, et al. Global cancer statistics 2018: GLOBOCAN estimates of incidence and mortality worldwide for 36 cancers in 185 countries. CA Cancer J Clin 2018;68:394-424.

2. Villanueva A. Hepatocellular Carcinoma. N Engl J Med 2019;380:1450-62.

3. Liu X, Chen Z, Yu M, et al. Safety of Simultaneous Hepatectomy and Splenectomy in the Treatment of Hepatocellular Carcinoma Complicated with Hypersplenism: A Meta-analysis. Gastroenterol Res Pract 2019;2019:9065845.

4. European Association for the Study of the Liver. EASL Clinical Practice Guidelines: Management of hepatocellular carcinoma. J Hepatol 2018;69:182-236.

5. Heimbach JK, Kulik LM, Finn RS, et al. AASLD guidelines for the treatment of hepatocellular carcinoma. Hepatology 2018;67:358-80.

6. Ishizawa T, Hasegawa K, Aoki T, et al. Neither multiple tumors nor portal hypertension are surgical contraindications for hepatocellular carcinoma. Gastroenterology 2008;134:1908-16.

7. Wu CC, Cheng SB, Ho WM, et al. Liver resection for hepatocellular carcinoma in patients with cirrhosis. $\mathrm{Br} \mathrm{J}$ Surg 2005;92:348-55.

8. Oh JW, Ahn SM, Kim KS, et al. The role of splenectomy in patients with hepatocellular carcinoma and secondary hypersplenism. Yonsei Med J 2003;44:1053-8.

9. Wu C, Ning H, Liu M, et al. Spleen mediates a distinct hematopoietic progenitor response supporting tumorpromoting myelopoiesis. J Clin Invest 2018;128:3425-38.

10. Nomura $Y$, Kage $M$, Ogata T, et al. Influence of 
splenectomy in patients with liver cirrhosis and hypersplenism. Hepatol Res 2014;44:E100-9.

11. Chen XP, Wu ZD, Huang ZY, et al. Use of hepatectomy and splenectomy to treat hepatocellular carcinoma with cirrhotic hypersplenism. Br J Surg 2005;92:334-9.

12. Hirooka M, Ishida K, Kisaka Y, et al. Efficacy of splenectomy for hypersplenic patients with advanced hepatocellular carcinoma. Hepatol Res 2008;38:1172-7.

13. Li W, Shen SQ, Wu SM, et al. Simultaneous hepatectomy and splenectomy versus hepatectomy alone for hepatocellular carcinoma complicated by hypersplenism: a meta-analysis. Onco Targets Ther 2015;8:2129-37.

14. Kong J, Shen S, Wang W. Synchronous hepatectomy and splenectomy vs hepatectomy for selected patients with hepatocellular carcinoma and clinically significant portal hypertension: A systematic review and meta-analysis. J Surg Oncol 2019;119:964-73.

15. Xie XL, Liu X, Ou J. Is synchronous hepatectomy and splenectomy superior to hepatectomy alone for selected patients with hepatocellular carcinoma and clinically significant portal hypertension? J Surg Oncol 2019;120:316-7.

16. Moher D, Liberati A, Tetzlaff J, et al. Preferred reporting items for systematic reviews and meta-analyses: the PRISMA statement. BMJ 2009;339:b2535.

17. Higgins JP, Altman DG, Gøtzsche PC, et al. The Cochrane Collaboration's tool for assessing risk of bias in randomised trials. BMJ 2011;343:d5928.

18. Stang A. Critical evaluation of the Newcastle-Ottawa scale for the assessment of the quality of nonrandomized studies in meta-analyses. Eur J Epidemiol 2010;25:603-5.

19. Parmar MK, Torri V, Stewart L. Extracting summary statistics to perform meta-analyses of the published literature for survival endpoints. Stat Med 1998;17:2815-34.

20. Higgins JP, Thompson SG, Deeks JJ, et al. Measuring inconsistency in meta-analyses. BMJ 2003;327:557-60.

21. Sutton AJ, Duval SJ, Tweedie RL, et al. Empirical assessment of effect of publication bias on meta-analyses. BMJ 2000;320:1574-7.

22. Wu CC, Cheng SB, Ho WM, et al. Appraisal of concomitant splenectomy in liver resection for hepatocellular carcinoma in cirrhotic patients with hypersplenic thrombocytopenia. Surgery 2004;136:660-8.

23. Yang T, He H, Yuan J, et al. Surgery for hepatocellular carcinoma presenting with variceal bleeding: The eastern experience. J Surg Oncol 2016;113:165-74.

24. Zhang X, Li C, Wen T, et al. Synchronous splenectomy and hepatectomy for patients with small hepatocellular carcinoma and pathological spleen: neutrophil to lymphocyte ratio changes can predict the prognosis. Oncotarget 2017;8:46298-311.

25. Li C, Zhao H, Zhao J, et al. Prognosis of patients with hepatocellular carcinoma and hypersplenism after surgery: a single-center experience from the People's Republic of China. Onco Targets Ther 2014;7:957-64.

26. Pei Y, Zhang Z, Mba'nbo-Koumpa AA, et al. Improved survival following splenectomy combined with curative treatments for hepatocellular carcinoma in Child B patients: A propensity score matching study. Hepatol Res 2019;49:177-88.

27. Nagasue N, Kohno H, Yamanoi A, et al. Role of splenectomy in hepatic resection for hepatocellular carcinoma associated with severe cirrhosis and hypersplenism. Hepatol Res 1999;14:35-48.

28. Jiang B, Chen X, Huang Z, et al. Surgical treatment of hepatocellular carcinoma with cirrhotic esophageal varices and hypersplenism: a 184 case report. Front Med China 2007;1:24-9.

29. Kim SH, Kim DY, Lim JH, et al. Role of splenectomy in patients with hepatocellular carcinoma and hypersplenism. ANZ J Surg 2013;83:865-70.

30. Forner A, Reig M, Bruix J. Hepatocellular carcinoma. Lancet 2018;391:1301-14.

31. Kawanaka H, Akahoshi T, Kinjo N, et al. Impact of antithrombin III concentrates on portal vein thrombosis after splenectomy in patients with liver cirrhosis and hypersplenism. Ann Surg 2010;251:76-83.

32. Kawanaka H, Akahoshi $\mathrm{T}$, Itoh $\mathrm{S}$, et al. Optimizing risk stratification in portal vein thrombosis after splenectomy and its primary prophylaxis with antithrombin III concentrates and danaparoid sodium in liver cirrhosis with portal hypertension. J Am Coll Surg 2014;219:865-74.

33. Bai DS, Xia BL, Zhang C, et al. Warfarin versus aspirin prevents portal vein thrombosis after laparoscopic splenectomy and azygoportal disconnection: A randomized clinical trial. Int J Surg 2019;64:16-23.

34. Zhang X, Li J, Shen F, et al. Significance of presence of microvascular invasion in specimens obtained after surgical 
treatment of hepatocellular carcinoma. J Gastroenterol Hepatol 2018;33:347-54.

35. Shen J, Liu J, Li C, et al. The Impact of Tumor Differentiation on the Prognosis of HBV-Associated

Cite this article as: Shi $\mathrm{XB}$, Feng JK, Wang JH, Jiang XQ. Does splenectomy significantly improve the prognosis of hepatocellular carcinoma patients with hypersplenism? A systematic review and meta-analysis. Ann Transl Med 2021;9(8):641. doi: 10.21037/atm-20-6748
Solitary Hepatocellular Carcinoma Following Hepatectomy: A Propensity Score Matching Analysis. Dig Dis Sci 2018;63:1962-9. 
Table S1 Demographics and characteristics of HCC patients in the splenectomy and non-splenectomy groups

\begin{tabular}{|c|c|c|c|c|c|c|c|c|c|c|c|c|c|c|c|c|c|c|c|c|c|c|c|c|c|c|c|c|c|c|}
\hline \multirow[t]{2}{*}{ Study } & \multirow{2}{*}{\multicolumn{2}{|c|}{$\begin{array}{c}\begin{array}{c}\text { Number of } \\
\text { patients }\end{array} \\
\text { SPT NSPT }\end{array}$}} & \multicolumn{2}{|c|}{$\begin{array}{l}\text { Age } \\
\text { (years) }\end{array}$} & \multicolumn{2}{|c|}{$\begin{array}{c}\text { Gender } \\
\text { (male/female) }\end{array}$} & \multicolumn{2}{|c|}{$\begin{array}{l}\text { Hepatitis } \\
\text { virology } \\
(\mathrm{HBV} / \mathrm{HCV})\end{array}$} & \multicolumn{2}{|c|}{$\begin{array}{l}\text { Child-Pugh } \\
\text { classification } \\
\text { (A/B) }\end{array}$} & \multicolumn{2}{|c|}{$\begin{array}{c}\text { Tumor } \\
\text { diameter }(\mathrm{cm})\end{array}$} & \multicolumn{2}{|c|}{$\begin{array}{l}\text { Tumor number } \\
\text { (solitary/ } \\
\text { multiple) }\end{array}$} & \multicolumn{2}{|c|}{$\begin{array}{c}\text { AFP } \\
\text { (ng/mL) }\end{array}$} & \multicolumn{2}{|c|}{$\begin{array}{l}\text { WBC } \\
\left(10^{\circ} / L\right)\end{array}$} & \multicolumn{2}{|c|}{$\begin{array}{l}\text { PLT } \\
\left(10^{\circ} / L\right)\end{array}$} & \multicolumn{2}{|c|}{$\begin{array}{c}\mathrm{TBil} \\
\text { (mg/dL) }\end{array}$} & \multicolumn{2}{|c|}{$\begin{array}{c}\mathrm{MVI} \\
\text { (presence/ab- } \\
\text { sence) }\end{array}$} & \multicolumn{2}{|c|}{$\begin{array}{c}\text { Tumor } \\
\text { differentiation } \\
\text { (well-moderate/ } \\
\text { poor) }\end{array}$} & \multicolumn{2}{|c|}{$\begin{array}{l}\text { Esophageal } \\
\text { varices } \\
\text { (presence/ } \\
\text { absence) }\end{array}$} & \multicolumn{2}{|c|}{$\begin{array}{c}\text { Hypersplenism } \\
\text { (slight/moderate/ } \\
\text { severe) }\end{array}$} \\
\hline & & & SPT & NSPT & SPT & $\begin{array}{l}\text { NSPT } \\
\end{array}$ & SPT & NSPT & SPT & $\begin{array}{l}\text { NSPT } \\
\end{array}$ & SPT & NSPT & SPT & NSPT & SPT & NSPT & SPT & NSPT & SPT & NSPT & SPT & NSPT & SPT & NSPT & SPT & NSPT & SPT & NSPT & SPT & NSPT \\
\hline Nagasue et al. & 26 & 36 & $\begin{array}{c}16 / 10 \\
(\leqslant 65 />65)\end{array}$ & $\begin{array}{c}16 / 10 \\
(\leq 65 />65)\end{array}$ & $15 / 11$ & $31 / 5$ & $7 / 19$ & $7 / 29$ & $0 / 17$ & $0 / 29$ & $\begin{array}{c}9 / 12 / 5(<3 / 3- \\
5 />5)\end{array}$ & $\begin{array}{c}16 / 12 / 8 \\
(<3 / 3-5 />5)\end{array}$ & $20 / 6$ & $32 / 4$ & NA & NA & $\begin{array}{c}19 / 7 \\
(\leq 4 />4)\end{array}$ & $\begin{array}{l}11 / 25 \\
(\leq 4 />4)\end{array}$ & $\begin{array}{c}21 / 5 \\
(\leq 100 />100)\end{array}$ & $\begin{array}{c}16 / 20 \\
(\leq 100 />100)\end{array}$ & $\begin{array}{c}5 / 21 \\
(<1 / \geq 1)\end{array}$ & $\begin{array}{l}24 / 12 \\
(<1 / 11)\end{array}$ & $\mathrm{NA}$ & NA & NA & NA & $19 / 7$ & $12 / 24$ & NA & NA \\
\hline Wu et al. & 41 & 485 & $60.1 \pm 8.7$ & $59.4 \pm 12.1$ & $28 / 13$ & $392 / 93$ & $23 / 18$ & $287 / 198$ & $29 / 10$ & $390 / 75$ & $4.62 \pm 2.69$ & $6.96 \pm 4.22$ & $34 / 7$ & $393 / 92$ & $1188 \pm 24$ & $1119 \pm 247$ & $2.45 \pm 0.35$ & $6.25 \pm 1.20$ & $38.2 \pm 2.1$ & $152.3 \pm 3.1$ & $1.53 \pm 0.21$ & $1.02 \pm 0.14$ & $6 / 35$ & $169 / 316$ & $38 / 3$ & $336 / 149$ & $23 / 18$ & $372 / 413$ & NA & NA \\
\hline Jiang et al. & 61 & 82 & $46.6 \pm 9.9$ & $44.8 \pm 10.2$ & $59 / 2$ & $77 / 5$ & $53 / 8$ & $70 / 12$ & $25 / 36$ & $38 / 44$ & $\begin{array}{c}2 / 46 / 13 \\
(<2 / 2-5 />5)\end{array}$ & $\begin{array}{c}2 / 46 / 13 \\
(<2 / 2-5 />5)\end{array}$ & $48 / 13$ & $66 / 16$ & $\begin{array}{c}24 / 37 \\
(<20 / \geq 20)\end{array}$ & $\begin{array}{c}25 / 57 \\
(<20 / \geq 20)\end{array}$ & $2.22 \pm 0.67$ & $3.25 \pm 0.46$ & $35.5 \pm 12.9$ & $11.5 \pm 8.6$ & NA & NA & NA & NA & NA & NA & $61 / 0$ & $82 / 0$ & $0 / 25 / 36$ & $82 / 0 / 0$ \\
\hline Hirooka et al. & 22 & 12 & $55.8 \pm 10.3$ & $62.1 \pm 7.0$ & $17 / 5$ & $12 / 0$ & $3 / 19$ & $3 / 9$ & $14 / 8$ & $8 / 4$ & NA & NA & NA & NA & NA & NA & $\begin{array}{c}3.20 \\
(1.42-8.50)\end{array}$ & $\begin{array}{c}3.90 \\
(2.53-5.75)\end{array}$ & $61 \pm 14$ & $73 \pm 4$ & NA & $\mathrm{NA}$ & NA & NA & NA & NA & NA & NA & NA & NA \\
\hline Kim et al. & 19 & 39 & $51(38-67)$ & $56(38-74)$ & $13 / 6$ & $33 / 6$ & $16 / 3$ & $29 / 9$ & $19 / 0$ & $39 / 0$ & $3(1-5)$ & $2.8(1-5)$ & NA & NA & NA & NA & $\begin{array}{c}3.49 \\
(1.63-6.37)\end{array}$ & $\begin{array}{c}5.25 \\
(0.65-8.24)\end{array}$ & $\begin{array}{c}61 \\
(23-257)\end{array}$ & $\begin{array}{c}141 \\
(53-285)\end{array}$ & $\begin{array}{c}1.0 \\
(0.5-1.6)\end{array}$ & $\begin{array}{c}0.7 \\
(0.3-1.3)\end{array}$ & $6 / 11$ & $19 / 20$ & $8 / 6$ & $24 / 9$ & $10 / 9$ & $8 / 31$ & NA & NA \\
\hline Lietal. & 60 & 121 & $55.2 \pm 9.8$ & $55.8 \pm 11.0$ & $46 / 14$ & $100 / 21$ & $55 / 4$ & $105 / 17$ & $52 / 8$ & 107/14 & $\begin{array}{c}47 / 13 \\
(<5 / \geq 5)\end{array}$ & $\begin{array}{l}72 / 49 \\
(<5 / \geq 5)\end{array}$ & $47 / 13$ & $102 / 19$ & $\begin{array}{c}19 / 41 \\
(<20 / \geq 20)\end{array}$ & $\begin{array}{c}48 / 73 \\
(<20 / \geq 20)\end{array}$ & $3.4 \pm 0.8$ & $4.3 \pm 1.4$ & $70.5 \pm 21.6$ & $88.3 \pm 29.8$ & NA & NA & $5 / 55$ & $9 / 112$ & $42 / 18$ & $76 / 45$ & NA & NA & $56 / 4 / 0$ & $117 / 4 / 0$ \\
\hline Yang et al. & 31 & 44 & $51.0 \pm 8.4$ & $52.0 \pm 8.9$ & $28 / 3$ & $38 / 6$ & $31 / 0$ & $43 / 1$ & 20/11 & $24 / 20$ & $\begin{array}{c}16 / 15 \\
(<3 / \geq 3)\end{array}$ & $\begin{array}{l}21 / 23 \\
(<3 / \geq 3)\end{array}$ & $25 / 6$ & $36 / 8$ & $\begin{array}{c}14 / 17 \\
(<20 / 220)\end{array}$ & $\begin{array}{c}18 / 26 \\
(<20 / \geq 20)\end{array}$ & NA & NA & $62 \pm 38$ & $70 \pm 31$ & $1.25 \pm 0.52$ & $1.07 \pm 0.42$ & $12 / 19$ & $23 / 21$ & 9/22 & $10 / 34$ & $31 / 0$ & $44 / 0$ & NA & NA \\
\hline Zhang et al. & 110 & 271 & $50.2 \pm 9.7$ & $50.0 \pm 14.2$ & $91 / 19$ & 229/42 & $103 / 7$ & $253 / 18$ & NA & NA & $\begin{array}{c}61 / 49 \\
(<3 / \geq 3)\end{array}$ & $\begin{array}{l}151 / 120 \\
(<3 / \geq 3)\end{array}$ & $100 / 10$ & 239/32 & $\begin{array}{c}77 / 33 \\
(\leq 400 />400)\end{array}$ & $\begin{array}{c}193 / 78 \\
(\leq 400 />400)\end{array}$ & $3.01 \pm 1.48$ & $4.53 \pm 1.66$ & $53.48 \pm 35.63$ & $75.34 \pm 18.69$ & $1.04 \pm 0.39$ & $0.97 \pm 0.40$ & $15 / 95$ & $55 / 216$ & $78 / 32$ & $162 / 109$ & NA & NA & $16 / 72 / 22$ & $226 / 39 / 6$ \\
\hline Peietal. & 95 & 95 & $52.0 \pm 11.1$ & $51.8 \pm 8.7$ & $82 / 13$ & $81 / 14$ & $89 / 6$ & $90 / 5$ & 0/95 & $0 / 95$ & $\begin{array}{l}48 / 47 \\
(<3 / \geq 3)\end{array}$ & $\begin{array}{c}61 / 49 \\
(<3 / \geq 3)\end{array}$ & $88 / 7$ & $87 / 8$ & $\begin{array}{c}36 / 59 \\
(<20 / \geq 20)\end{array}$ & $\begin{array}{c}42 / 53 \\
(<20 / \geq 20)\end{array}$ & $3.02 \pm 1.58$ & $3.07 \pm 0.71$ & $48.80 \pm 21.58$ & $49.48 \pm 12.60$ & $1.39 \pm 0.73$ & $1.44 \pm 1.04$ & NA & NA & NA & NA & $95 / 0$ & $95 / 0$ & NA & NA \\
\hline
\end{tabular}

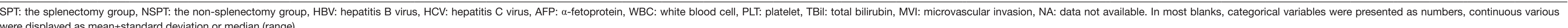


A

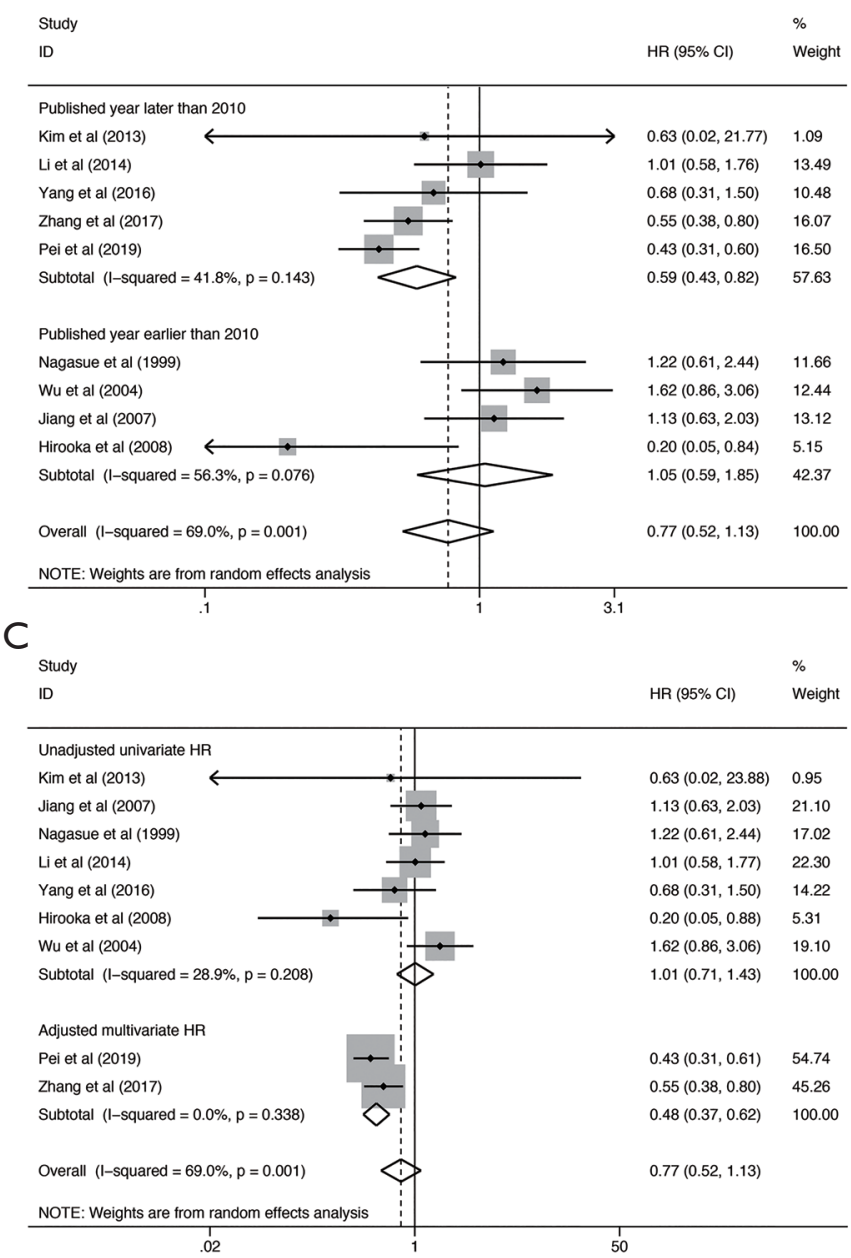

B

Study

ID

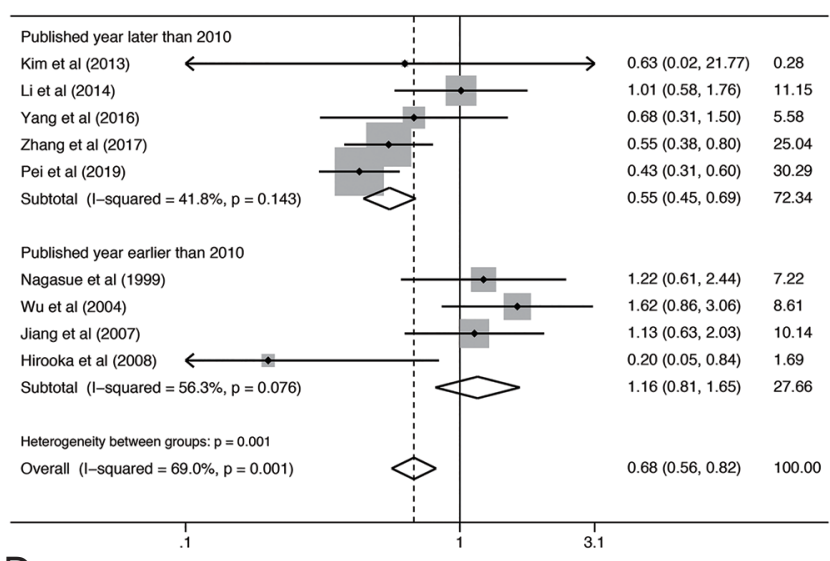

D

Study

HR $(95 \%$ Cl) $\quad$ Weight

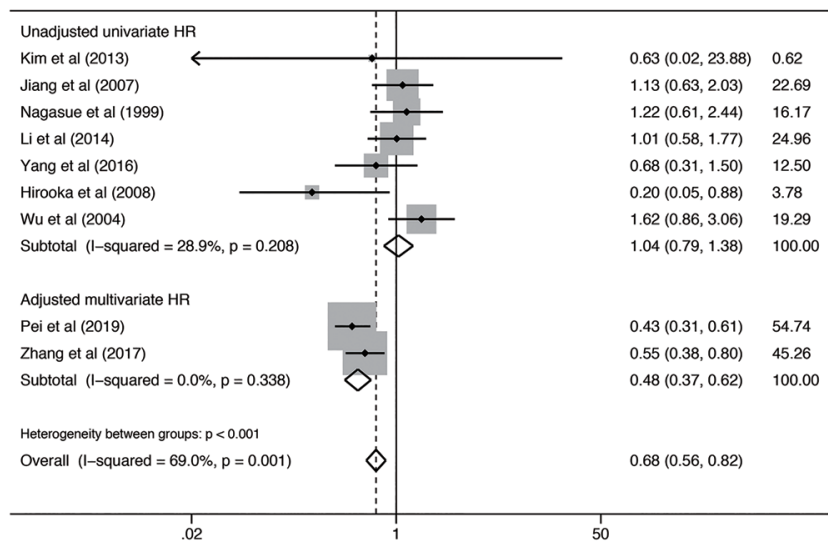

Figure S1 Forest plots of subgroup analyses according to the published year (later than 2010 vs. earlier than 2010) and the type of HR (unadjusted univariate HR vs. adjusted multivariate HR) for overall survival. (A) Forest plot of subgroup analysis according to the published year using the random-effects model; (B) Forest plot of subgroup analysis according to the published year using the fixed-effects model; (C) Forest plot of subgroup analysis according to the type of HR using the random-effects model; (D) Forest plot of subgroup analysis according to the type of HR using the fixed-effects model. Abbreviation: HR, hazard ratio. 
A

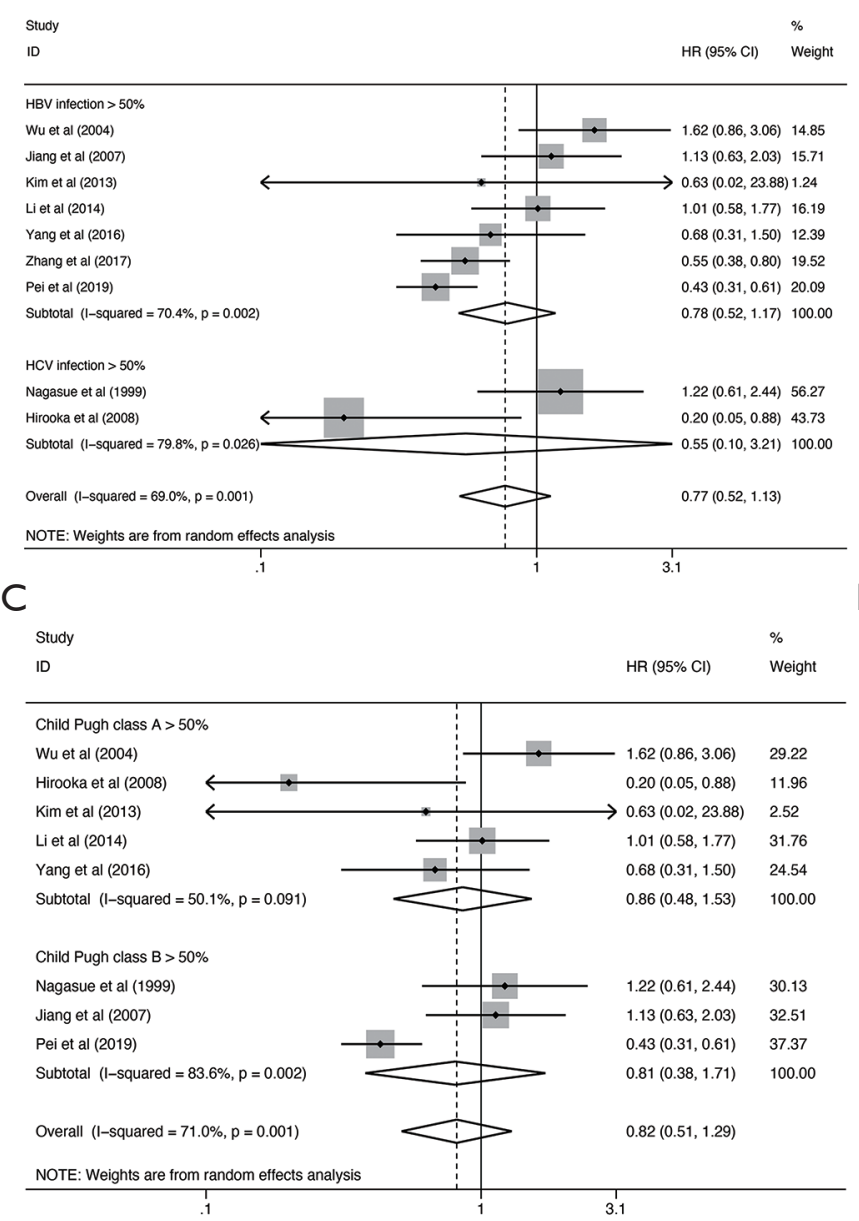

B

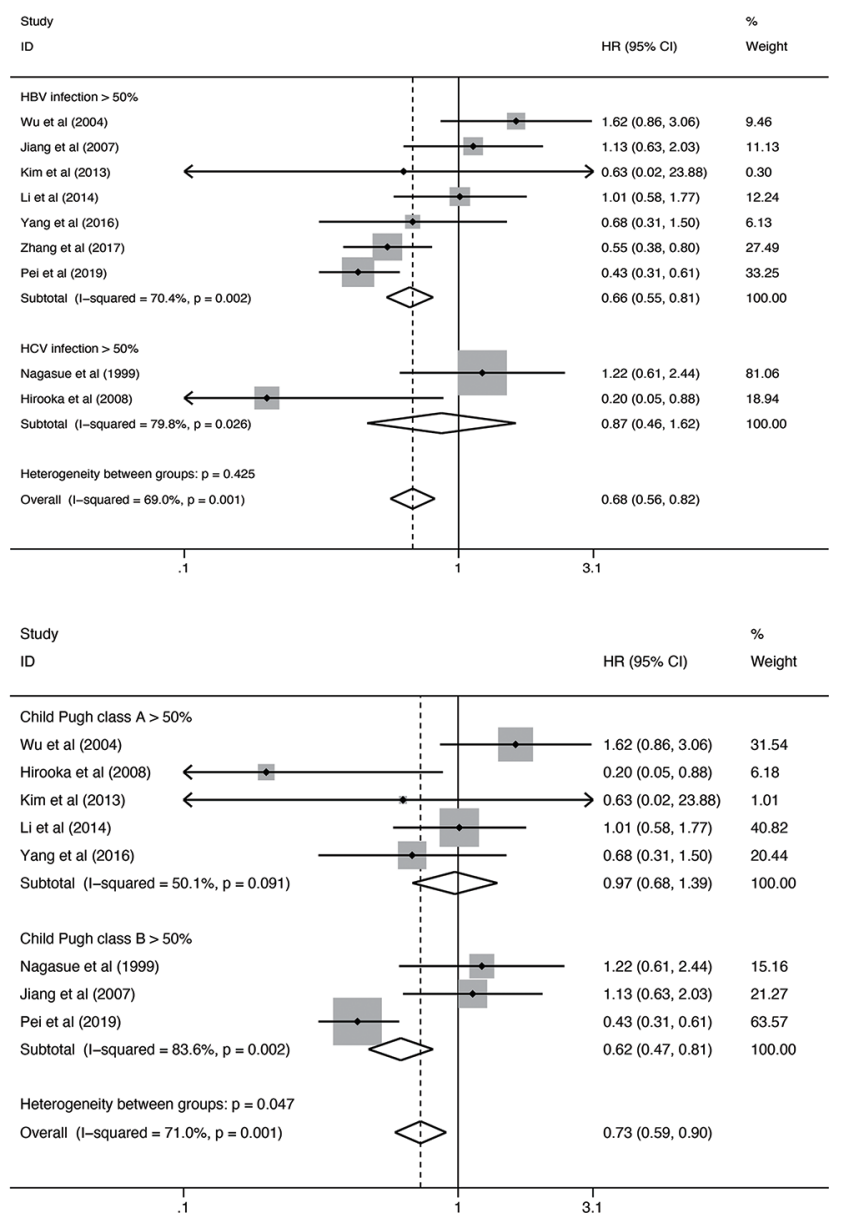

Figure S2 Forest plots of subgroup analyses according to the hepatitis viral background (HBV $>50 \%$ vs. HCV $>50 \%$ ) and the Child-Pugh grade (class $\mathrm{A}>50 \%$ vs. class $\mathrm{B}>50 \%$ ) for overall survival. (A) Forest plot of subgroup analysis according to the hepatitis viruses using the random-effects model; (B) Forest plot of subgroup analysis according to the hepatitis viruses using the fixed-effects model; (C) Forest plot of subgroup analysis according to the Child-Pugh grade using the random-effects model; (D) Forest plot of subgroup analysis according to the Child-Pugh grade using the fixed-effects model. Abbreviations: HBV, hepatitis B virus; HCV, hepatitis C virus. 
A

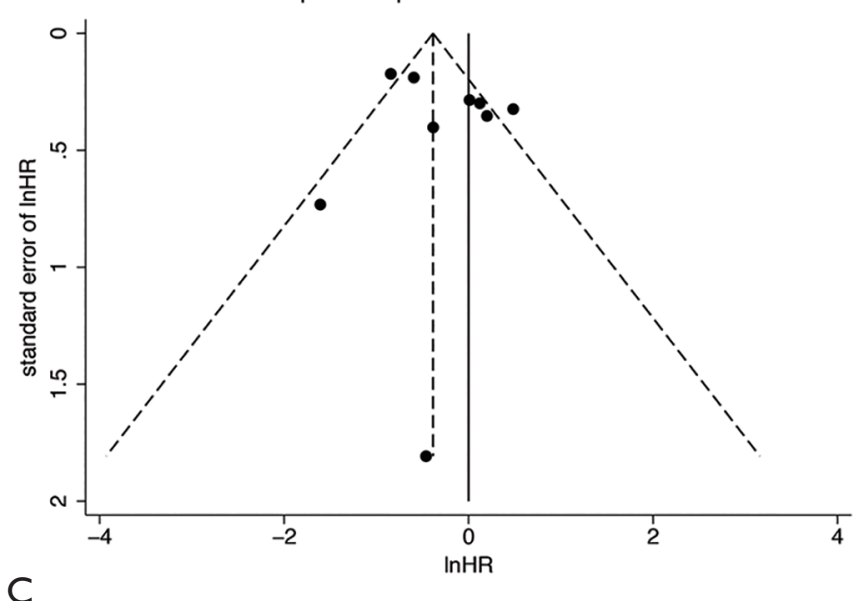

B Funnel plot with pseudo $95 \%$ confidence limits

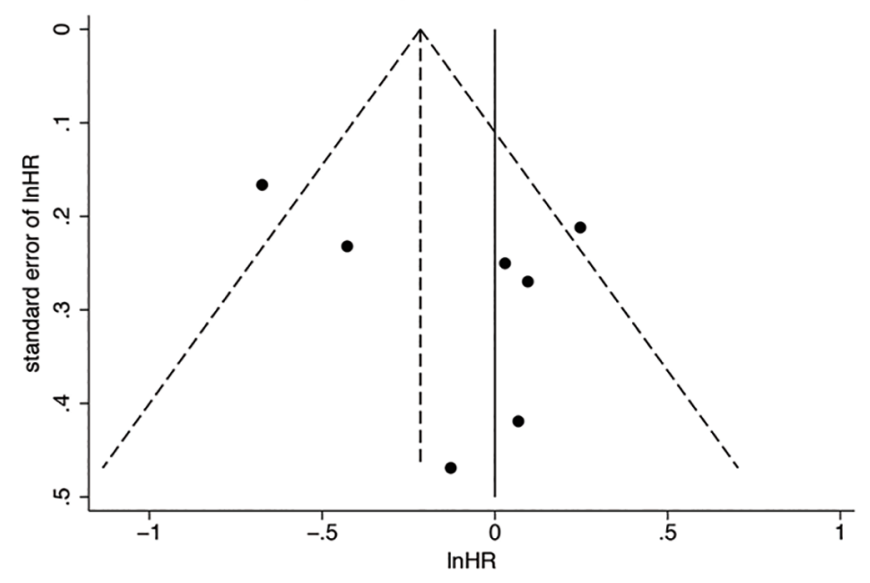

\begin{tabular}{lcc}
\hline & Overall survival & Disease-free survival \\
\hline Number of studies & 9 & 7 \\
P values for Begg's test & 0.917 & 0.456 \\
P values for Egger's test & 1.000 & 0.287 \\
\hline
\end{tabular}

Figure S3 Publication bias of the included studies for overall survival and disease-free survival. (A) Funnel plot of overall survival; (B) Funnel plot of disease-free survival; (C) Quantitative assessment of the publication bias using the Begg's and Egger's tests.
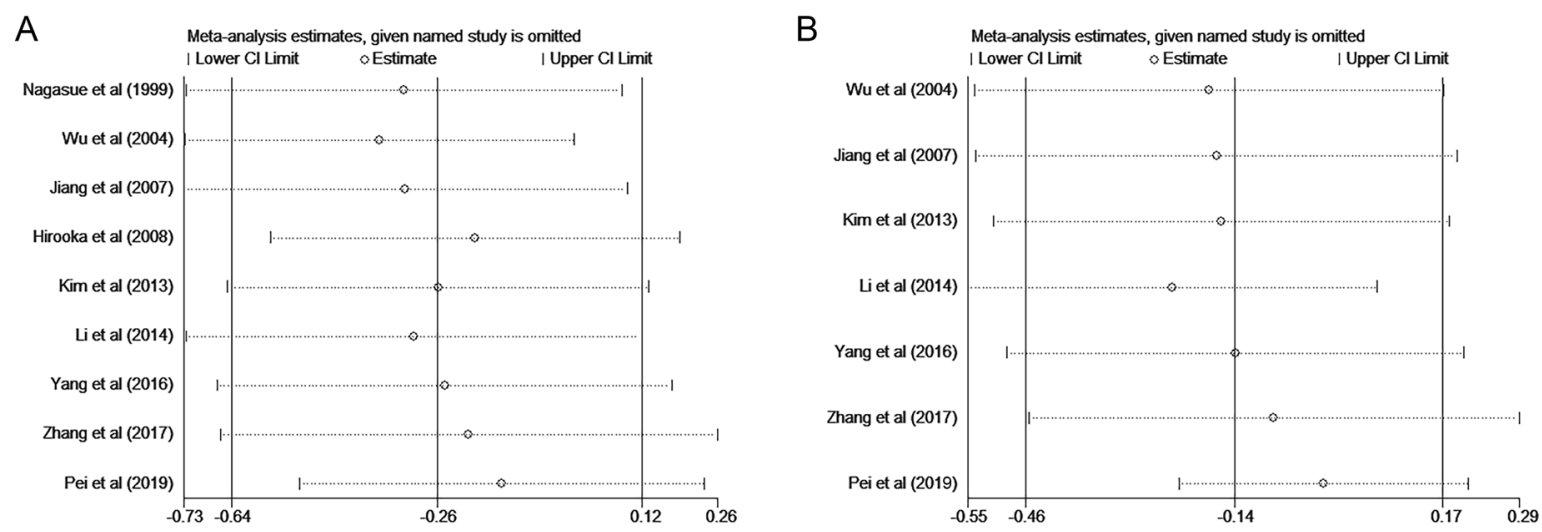

Figure S4 Sensitivity analyses for the evaluation of potential heterogeneity of overall survival and disease-free survival. (A) sensitivity analysis of overall survival; (B) sensitivity analysis of disease-free survival. 